\title{
A LUTA CONTINUA? A GUERRA EM MOÇAMBIQUE EM PERSPECTIVAS MÚLTIPLAS
}

MOURIER-GENOUD, Eric; CAHEN, Michel; ROSÁRIO, Domingos M. (orgs.). The War Within: new perspectives on the civil war in Mozambique, 1976-1992. Suffolk: James Curry; Nova York: Boydell \& Brewer, 2018. 268p.

$U_{\text {ma característica trágica com- }}$ partilhada pela história nacional de alguns países africanos é a emergência de conflitos militares dentro de suas próprias fronteiras que, via de regra, estão marcados por uma combinação variável de fatores e atores internos e externos - de um lado, a explosão de tensões e clivagens sociais que o regime político implantado após a independência não foi capaz de resolver, e em alguns casos agravou; de outro, a incidência de interesses econômicos e geoestratégicos que condicionaram a participação de outros Estados, empresas multinacionais e órgãos multilaterais. Na década de 1960, essa dinâmica alimentou conflagrações sangrentas no Congo-Léopoldville, nos Camarões e na Nigéria; após a independência dos territórios africanos submetidos à dominação portuguesa, Angola e Moçambique viram seus nomes incluídos nessa malfadada lista. Em Moçambique, diferente de Angola, a hegemonia política e militar do novo regime demorou alguns anos a ser seriamente desafiada. Embora tenha havido uma resistência armada localizada na Zambézia desde 1976, foi a partir do início da década seguinte que uma situação de guerra interna se generalizou, prolongando-se até 1992, quando foi assinado o Acordo Geral de Paz.

Em uma conjuntura intelectual marcada pela Guerra Fria, por uma simpatia difusa pelo Terceiro Mundo e pela incômoda resiliência do apartheid na África Austral, a própria forma de nomear o conflito que opôs o governo da Frente de Libertação de Moçambique (Frelimo) e a guerrilha da Resistência Nacional Moçambicana (Renamo) esteve no cerne de uma disputa que transbordou das falas inflamadas dos comandantes político-militares para o pacato mundo dos historiadores e cientistas sociais. A maior parte dos analistas falava de uma "guerra 
de desestabilização" dirigida pela África do Sul; outros acreditavam tratar-se de uma "guerra civil" ocasionada pela resistência aos programas de modernização autoritária propugnados pelo partido único, autoproclamado marxista-leninista em 1977.

Como já se vê desde a capa, este livro coletivo assume decididamente a designação "guerra civil", apostando na capacidade heurística dos níveis mais internos de análise. Fruto de um seminário realizado em 2012 em Maputo, a obra está dividida em sete capítulos, distribuídos em três partes de abrangência regional, além de uma introdução, uma conclusão e uma extensa bibliografia temática que, embora não comentada, representa um importante instrumento de pesquisa acadêmica. A primeira parte, dedicada ao centro e ao norte do país, reúne quatro capítulos; a segunda, centrada nos acontecimentos no sul, dois; a terceira parte é composta por um único capítulo, que se destina a encaixar o fenômeno da guerra nas dinâmicas globais do poder e suas transformações no fim da década de 1980.

Talvez como resultado do processo mesmo de sua construção, o livro não se destaca pela regularidade na forma de apresentação, na escala de observação, no escopo temático ou na profundidade analítica dos diversos capítulos, nem por uma cobertura regional sistemática do território atingido pela guerra. O plano geral da obra se assemelha mais a uma bricolagem, o que em si não é um ponto negativo, considerando a complexidade, a cronologia variável e as diferentes dinâmicas locais do próprio fenômeno. Ficamos assim com a impressão de poder observar cenas da conflagração em Moçambique a partir de uma sequência de distintos enquadramentos - a maior parte em close-up, outros em plano de conjunto.

O objetivo do seminário que deu origem ao livro era aproveitar a emergência recente de um grande conjunto de fontes, especialmente arquivos provinciais e de instituições religiosas, além de uma maior disponibilidade de memórias publicadas, mas, principalmente, de depoimentos orais. $\mathrm{O}$ acesso a realidades empíricas locais e a certos aspectos particulares da dinâmica da guerra até então muito pouco estudados se reflete na maior parte dos capítulos, que mantêm uma orientação bastante descritiva, extremamente útil para os acadêmicos que têm o conflito como seu objeto primário de pesquisa, mas talvez demasiado minuciosa para o gosto do público mais amplo.

Os organizadores avançam, já na introdução, três propostas norteadoras. Uma delas diz respeito precisamente à exploração de novas fontes como forma de abrir novas perspectivas de entendimento. Aponta-se também a necessidade de ultrapassar o foco na Renamo que caracteriza a maior parte da bibliografia, abrindo o leque para levar em consideração um conjunto de outros atores sociais, como os vários níveis do governo e 
suas agências, o exército nacional, a igreja católica, empresas privadas e organizações não governamentais e, especialmente, os camponeses - que são representados ao mesmo tempo como vítimas da guerra e grupo orgânico que por meio do conflito expressava suas demandas políticas. Finalmente, propõe-se encarar a guerra como um fato social total, incorporando na investigação uma série de processos sociais, culturais, religiosos, políticos e econômicos que se entrelaçavam para conformar a experiência vivida da conflagração. Como veremos, essas propostas são seguidas de forma irregular pelos diferentes autores.

Os três primeiros capítulos lidam com o desenvolvimento da guerra em duas das províncias do centro-norte do país. O texto que abre o volume, de autoria de Sérgio Chichava, trata da emergência dos movimentos armados antigovernamentais na Zambézia, particularmente o Partido Revolucionário de Moçambique (PRM). O segundo capítulo, escrito por Domingos Manuel do Rosário, toma a evolução do conflito em Nampula como base para seu argumento sobre a existência de um projeto político, e não apenas militar, por parte da Renamo. Já o terceiro, a cargo de Corinna Jentzsch, investiga em ambas as províncias o fenômeno dos "naparamas", milícias de autodefesa que derivavam sua considerável eficácia de poderes sobrenaturais investidos em seus integrantes. Essas contribuições são o resultado de três diferentes pesquisas primárias que recorrem em graus variáveis a fontes até então pouco visitadas dos arquivos dos governos das duas províncias e de arquivos portugueses, além da imprensa moçambicana do período e de grande número depoimentos orais.

Os dois primeiros textos, mais centrados nos arquivos provinciais, procuram retratar a guerra como um assunto eminentemente moçambicano. Sérgio Chichava faz uma arqueologia do surgimento do PRM ainda em 1976, como sucessor de outras dissidências nacionalistas. Longe de se constituírem como instrumentos da contrainsurgência portuguesa, como alegava a Frelimo, esses antecessores seriam fruto de diferendos regionais e, em menor medida, ideológicos, no seio da elite nacionalista, só mais tarde instrumentalizados pelo governo colonial. O autor aponta também um quadro de insatisfação latente na região, cuja origem situa em processos coloniais do início do século XX, agravado pelas medidas de modernização acelerada impostas ao campo após a independência - como a relocação forçada da população dispersa para "aldeias comunais", concebidas para racionalizar a oferta de serviços públicos no interior e, também, para fomentar e controlar a produção agrícola da qual o Estado dependia financeiramente. De fato, Chichava encontra nos arquivos do próprio governo indicações de forte apoio popular ao PRM nas zonas rurais da província, o que é compatível com o fenômeno 
do Wotcha Weka!, ou o incêndio das aldeias comunais, incentivado pelo PRM mas encampado pelos próprios camponeses, que em seguida retornavam aos locais que haviam sido obrigados a abandonar, ou seguiam para as bases do PRM no Maláui. A imagem assim desenhada de um movimento orgânico e fundamentalmente moçambicano de resistência à modernização autoritária, no entanto, contrasta com três evidências apresentadas pelo próprio autor. Em primeiro lugar, a restrição do alcance das ações armadas do PRM à faixa fronteiriça com o Maláui (cujo apoio o texto relativiza, talvez exageradamente). Em segundo lugar, o que chama de "confusão" da bibliografia entre PRM e África Livre, uma estação de rádio criada pelo regime segregacionista da Rodésia e gerida por moçambicanos, que transmitia propaganda anti-Frelimo tanto do PRM quanto da Renamo. Finalmente, as seguidas mudanças de lealdade tanto da direção do PRM (que se integra à Renamo, depois se separa e por fim se torna uma milícia de autodefesa subordinada à Frelimo) quanto da população camponesa (que transfere seu apoio do PRM para a Renamo, depois aposta na terceira via representada pelos naparamas, os quais finalmente também são cooptados pela Frelimo). Por ora, tomemos nota dessa intrigante volatilidade do "apoio" camponês, que nos acompanhará na leitura da obra até o fim.

Domingos Manuel do Rosário, por sua vez, pretende enxergar na estratégia militar adotada pela Renamo na província de Nampula um projeto político de mais longo prazo. $\mathrm{O}$ autor reconhece que o movimento armado de oposição foi, de início, uma criação externa, mas ressalta que sua transformação posterior em guerrilha com grandes contingentes e capaz de estender seu teatro de operações para toda a província demanda a consideração séria de fatores internos. Rosário acredita que a política de violência adotada pela Renamo, presente na província desde 1982, obedecia a um cálculo político de construção de uma base social. Essa violência dirigia-se contra absolutamente tudo o que pudesse simbolizar a presença do poder de Estado exercido pela Frelimo. As aldeias comunais constituíam talvez o alvo mais visível, mas postos administrativos e policiais, armazéns e lojas estatais, meios de comunicação e transporte, assim como escolas e hospitais, eram igualmente visados. A Renamo procurava ainda eliminar fisicamente as "estruturas" da Frelimo, ou seja, os agentes do partido-Estado com qualquer capacidade dirigente, em especial os integrantes dos Grupos Dinamizadores (órgãos de mobilização política de base, e subsidiariamente de repressão política, implantados em espaços de trabalho, escolas, bairros e aldeias). Segundo Rosário, as ações militares tinham um duplo objetivo: sabotar a infraestrutura física e humana para inviabilizar a operação do Estado, e recrutar novos guerrilheiros. Para 
isso, contavam não apenas com a insatisfação geral diante das políticas da Frelimo, mas também com os efeitos nocivos da violenta repressão, por parte das "estruturas" e de um exército moçambicano desorganizado e indisciplinado, às aldeias suspeitas de colaborar com a Renamo. O pior é que, para o governo, toda a população era suspeita, porque, ao que parece, não tinha se engajado suficientemente na luta de libertação. Aproveitando-se do quadro assim instituído de "Estado contra sociedade", a Renamo passaria, a partir de 1990, a desenvolver nas regiões que controlava os embriões de um governo civil, em busca de uma legitimidade de mais longa duração, visando o arranjo multipartidário que já se adivinhava como horizonte pós-guerra. As "zonas libertadas" da Renamo combinavam uma retórica política inequivocamente decalcada da Frelimo e o recurso a uma administração indireta herdada do tempo colonial, com a reinstauração das "chefias tradicionais" que haviam sido liminarmente extintas pelo Estado independente.

A narrativa de Corinna Jentzsch depende mais fortemente de depoimentos orais e está interessada na relação entre os aspectos espirituais e as dinâmicas da guerra, notadamente o fenômeno dos naparamas, já abordado de passagem nos dois capítulos anteriores. Aqui, mais uma vez, a questão do "apoio" da população camponesa está no centro do argumento: para a autora, a Renamo logrou um rápido crescimento em Nampula e na Zambézia porque, diferente do sul, a população não havia sido suficientemente mobilizada pela Frelimo e acalentava ressentimentos por sua marginalização nos assuntos nacionais. Foi no seio dessa mesma população, entretanto, que emergiram estratégias de autodefesa contra ambos os lados do conflito. Os naparamas surgiram em 1988 como uma dessas estratégias: milícias, armadas apenas com catanas, formadas localmente após a intervenção de um curandeiro que "vacinava" os futuros integrantes contra as balas. No campo de batalha, para que a vacina não perdesse sua eficácia, era necessário avançar sem nunca recuar ou olhar para trás, e sem ficar atrás de nenhum outro combatente, em dia claro e em campo aberto. Essa performance tinha um efeito muito palpável sobre os soldados inimigos, que geralmente debandavam sob a carga dos naparamas. Jentzsch rastreia as trajetórias dos principais curandeiros, buscando identificar sua origem, e apontando um processo de acirrada competição simbólica entre suas capacidades sobrenaturais; alguns curandeiros eram eles próprios chefes tradicionais, outros tornaram-se comandantes militares de suas próprias unidades. A Frelimo inicialmente tolerou essas milícias comunitárias e em seguida integrou-as em seu cálculo militar; a Renamo buscou rapidamente uma contramedida, promovendo uma vacinação semelhante de suas milícias, que as 
tornassem capazes de matar os naparamas utilizando lanças (algo que estava fora do alcance dos soldados regulares e seus fuzis). Não deixa de ser notável como mais uma vez o "apoio" da população camponesa permanece elusivo: como se poderá afinal conciliar a reiterada falta de legitimidade da Frelimo com o fato de que a iniciativa autônoma dos camponeses terminou se orientando fundamentalmente contra a Renamo, que supostamente era a expressão de sua resistência à modernização autoritária? E, se a Renamo tinha um projeto político desde o início, como defendem Chichava e Rosário, em que sentido não se tratava apenas de uma outra espécie de modernização autoritária? Por outro lado, seriam "camponeses" e "modernização" termos com significados assim tão distantes? É curioso que o vocabulário naparama remeta precisamente a um dos processos mais emblemáticos (e mágicos) da modernização autoritária colonial na África: a disseminação da biomedicina ocidental, com suas vacinas.

Fechando a primeira parte do livro, Michel Cahen acrescenta um pouco de aventura ao volume, debruçando-se sobre parte de uma série documental capturada pelas forças governamentais após o ataque à principal base da Renamo em 1985, e desde então desaparecida. A Frelimo publicou, naquele mesmo ano, excertos cuidadosamente escolhidos dessa documentação de modo a comprovar a continuidade da participação sul-africana na guerra, mesmo após o Acordo de Nkomati, assinado no ano anterior, pelo qual África do Sul e Moçambique se comprometiam a cessar o apoio que até então prestavam respectivamente à Renamo e ao Congresso Nacional Africano (African National Congress, ANC). Para Cahen, ao contrário, a documentação a que teve acesso demonstra, no seu conjunto, quase nenhuma interferência sul-africana no cotidiano militar e muito pouco apoio material, ainda que a continuidade das relações seja indiscutível. Contrariando as expectativas da Frelimo, o acordo parece ter empurrado a Renamo para dentro do território moçambicano, reforçando uma tendência iniciada com a transformação da Rodésia em Zimbábue, em 1980. Isso acarretou uma profunda reorganização do aparato militar e, em última análise, um processo de maior internalização da guerra. A partir da transcrição de um grande conjunto de mensagens de rádio trocadas entre o comando geral e os responsáveis das várias regiões militares, o autor esboça mapas, faz estimativas sobre números de efetivos e delineia dinâmicas regionais, em particular o grande "movimento para o norte" planejado pela direção, construindo um material de referência de utilidade ímpar para os pesquisadores, diante da indisponibilidade das fontes originais. Cahen acredita que todas as ações militares estavam condicionadas por um cálculo político o qual tinha como objetivo último trazer a Frelimo para a mesa de negociação. 
O autor observa como as ordens para a intensificação dos ataques buscavam reforçar a posição negocial da Renamo, e como esse processo levou a um esforço para criar estruturas políticas (como observou Rosário para um período posterior). Essas estruturas eram responsáveis por convencer as populações sob controle militar de que as negociações eram, em si, um sinal de que a guerra estava sendo ganha.

A segunda parte do livro concentra-se sobre a porção sul do território, onde, em princípio, a Frelimo contava com um apoio popular muito mais sólido e a Renamo tinha dificuldades para se inserir no tecido social, o que teria resultado em uma violência muito mais brutal e generalizada. Os dois capítulos que compõem essa parte têm vereditos diferentes sobre esse pressuposto, sendo, aliás, bastante díspares também em outros aspectos. Enquanto Eric Morier-Genoud segue de perto as propostas analíticas enunciadas na introdução para fazer um grande panorama do conflito, articulando as transformações no Estado, na sociedade e na economia da província de Inhambane, o texto de Lily Bunker se preocupa com a experiência vivida da guerra em um pequeno distrito rural, a Ilha Josina Machel, na província de Maputo, dando voz à memória dos massacres e sequestros de seus habitantes, a partir dos depoimentos das vítimas e seus parentes.

A Ilha Josina Machel, como o nome já sugere, permaneceu ao longo de todo o conflito como um bastião da Frelimo - ali, os projetos de modernização do campo defendidos pelo Estado parecem ter sido incorporados sem grande resistência e até com certo entusiasmo. A ilha tornou-se uma aldeia comunal exemplar, cercada por cooperativas agrícolas e machambas estatais, visitada por mandatários estrangeiros como evidência do sucesso da revolução socialista. Por isso mesmo, a localidade configurou-se como um alvo privilegiado para os ataques da guerrilha, que chegou com força à região por volta de 1987. A Defesa Popular, um órgão de base tal como o Grupo Dinamizador, existia ali desde 1979. Entretanto, e apesar de este ser um dos locais mais bem defendidos da província, havia poucos com alguma formação militar, e uma pungente escassez de armas, de modo que a função dessa milícia era tentar organizar a fuga da população em caso de ataque, ou rastrear o destino dos homens, mulheres e crianças eventualmente sequestrados. Para Bunker, os sequestros afetaram profundamente a dinâmica local. Quem podia, emigrava, e quem ficava, deixava suas casas para ir dormir no mato ou na cidade mais próxima, defendida por uma cerca eletrificada. Em caso de captura, homens e meninos eram mantidos sob estreita vigilância por algum tempo, e em seguida obrigados a participar de ataques a suas próprias aldeias, para garantir que não pudessem voltar (aparentemente, em muitas áreas do sul a adesão voluntária à Renamo era praticamente inexistente, e esta era 
a forma padrão de recrutamento). Mulheres e meninas eram obrigadas a "casar" com guerrilheiros específicos, ou eram esporadicamente instadas a ter relações sexuais com homens diferentes. $\mathrm{O}$ retrato pintado por Bunker aponta para uma situação virtualmente oposta àquela observada nas províncias mais a norte, e para uma absoluta ilegitimidade da Renamo. Mesmo seus guerrilheiros eram ndau - uma etnia "estrangeira" reputada por seus poderes em feitiçaria - ou, pelo menos, são assim lembrados. De modo geral, apesar de a autora qualificar a memória dos habitantes da Ilha Josina Machel como fragmentada, verifica-se uma unanimidade impressionante nos depoimentos e no texto construído a partir deles. Há entretanto uma brecha: uma curandeira vivendo numa cidade próxima, viúva de um antigo chefe tradicional. Ela não só fornecia à Renamo preparados que conferiam poderes sobrenaturais aos guerrilheiros, como também atuava como agente de recrutamento. Em um ambiente tão marcadamente pró-Frelimo, é até difícil imaginar como uma situação como essa podia se registrar. Essa incongruência não desmerece $o$ exaustivo trabalho de pesquisa feito por Bunker, mas serve como lembrete de que as memórias de acontecimentos traumáticos que ademais implicam posicionamentos políticos no presente precisam ser tratados com uma dose adicional de atenção.

O texto de Morier-Genoud, em contraste com os demais capítulos das duas primeiras partes, abre significativamente o ângulo sobre o fenômeno da guerra. $\mathrm{O}$ autor recorre a um conjunto balanceado de fontes (entre depoimentos orais, arquivos e um trabalho de campo realizado ao longo de mais de duas décadas) para analisar o comportamento do Estado, da igreja católica e das ONGs, relacionando-os a aspectos ecológicos e econômicos que interferiram no desenvolvimento do conflito. $\mathrm{O}$ argumento se estrutura em torno da verificação da hipótese, hegemônica na bibliografia, de que a guerra teria um caráter diferente no sul, por conta da falta de legitimidade da Renamo, da relativa debilidade da chefia tradicional, e de um estranhamento étnico entre as populações locais e os guerrilheiros ndau que seriam maioria nos primeiros destacamentos a entrar na região. Morier-Genoud reconhece que a chegada da guerra a Inhambane, em fins de 1981, obedeceu a determinações externas, especialmente a necessidade de aproximar a atuação da guerrilha de suas linhas de suprimento, cuja responsabilidade passara para a África do Sul após o fim da Rodésia. Apesar de não poder se beneficiar de um grau significativo de descontentamento popular, o autor mostra que a Renamo soube se inserir em disputas locais no âmbito da chefia tradicional - a qual, apesar de oficialmente extinta, continuava operante e em relação ativa com as novas formas, técnicas e estruturas do poder político independente. Aparentemente, assim como no norte, a legitimidade da Frelimo 
foi estremecida por suas próprias respostas à presença da Renamo, em um quadro geral em que as receitas públicas despencavam e a capacidade técnica do governo estava comprometida por uma insidiosa falta de quadros e meios. A intensificação de uma política de aldeização apressada gerou descontentamento, mas o mais grave foi a proliferação de postos militares sem a garantia de seu aprovisionamento, em uma região que ainda não se recuperara da seca e da fome que haviam marcado os últimos anos da década anterior. Não seria propriamente um quadro de Estado contra sociedade, como aquele desenhado por Rosário, mas de destacamentos armados dispersos, organizados em campos adversários, mas cuja sobrevivência imediata dependia quase inteiramente da predação sobre a mesma população camponesa. Nesse sentido, a composição étnica dos diferentes grupos armados era irrelevante. Morier-Genoud mostra ainda como a igreja católica conseguiu se recuperar da hostilidade inicial da Frelimo, transformando suas estruturas internas para melhor lidar com os impactos da guerra sobre a população local, até se colocar numa posição de mediação entre os beligerantes e facilitar o advento da paz. De forma semelhante, o autor aponta como a catástrofe humanitária que se agravou a partir de meados da década de 1980 condicionou a criação de uma economia de guerra, que permitiu certa acumulação privada de capital, ao mesmo tempo que a oferta de serviços públicos terminou quase inteiramente delegada a ONGs, financiadas pela reaproximação da socialista Frelimo aos órgãos do capitalismo global e aos governos ocidentais. Neste capítulo, de fato, conseguimos observar de forma bem acabada as propostas analíticas da diversificação da ênfase em distintos participantes da guerra, e sua abordagem como fato social total.

A última parte do livro e seu único capítulo, escrito por Georgi Derluguian, ocupam um lugar curioso no plano geral da obra, parecendo contradizer cabalmente a orientação internalista e a escolha da experiência vivida da guerra como ponto de vista privilegiado para a elaboração de um quadro explicativo coerente. É verdade que Derluguian testemunhou o conflito, quando trabalhava na cooperação soviética em Moçambique, em meados da década de 1980, e utiliza essa experiência para embasar suas observações. Mas, de resto, assume uma abordagem macro-histórica preocupada em delinear as condições globais de possibilidade e as linhas de força tendenciais do sucesso da Frelimo enquanto movimento de libertação de 1965 a 1975, e de seu fracasso como governo revolucionário na década seguinte, propondo uma compreensão do conflito moçambicano como um episódio da transição global para a pós-modernidade (definida, de forma esquemática, como o período em que o capitalismo global se aproxima de seu ponto de 
saturação e as promessas iluministas de rápidas transformações positivas perdem seu apelo político e sua força emocional). Colocando em suspenso a profundidade estrutural das clivagens ideológicas da Guerra Fria, o autor aproxima os projetos da esquerda e da direita ao longo do século XX no que eles representavam de desenvolvimento industrial mais ou menos induzido pelo Estado, apontando o papel de continuação e radicalização assumido pelas revoluções socialistas em relação aos sistemas anteriores que lutaram para derrubar - a começar pela revolução soviética, que teria propiciado modelos organizacionais do partido, da política de massas e do Estado para o conjunto das experiências socialistas posteriores. Segundo esse raciocínio, o fracasso da Frelimo como partido-Estado não derivaria tanto de um excesso de stalinismo, mas de um stalinismo insuficiente: os líderes moçambicanos não estavam preparados (ou não tinham os meios) para reprimir com a necessária brutalidade sua população camponesa de forma a garantir sua conformidade com as políticas de coletivização e racionalização da produção agrícola que eram concebidas como base para a futura decolagem industrial. Derluguian segue oferecendo explicações macro-históricas para muitas das características mais íntimas da guerra em Moçambique evocadas nos capítulos anteriores, e, ainda que reconheça explicitamente a importância dos fatores internos, demonstra, com muita argúcia, o quanto abordagens demasiado internalistas são incapazes de fornecer uma explicação satisfatória do conflito. Em particular, ele chama a atenção para as "estruturas globais de oportunidade" que teriam determinado as opções ideológicas da Frelimo, de sua radicalização à esquerda na primeira década, passando por seu combate obstinado contra o apartheid após a independência, até sua reconversão liberal em torno do Acordo Geral de Paz. O próprio fim da guerra não pode ser pensado apenas internamente: a exaustão que tornou a paz desejável e urgente não era apenas das populações atingidas pela violência e pela fome, ou mesmo dos dois exércitos envolvidos, mas também dos regimes externos que os sustentavam, respectivamente a África do Sul e a União Soviética. Este capítulo entretanto é um ponto fora da curva, uma espécie de grilo falante a perturbar a direção geral das demais contribuições.

Tomado em seu conjunto, não há dúvidas de que este volume significa uma contribuição importante ao debate. A proposta de entender o significado da guerra a partir da perspectiva de múltiplos atores internos e a riqueza dos variados tipos documentais mobilizados são dois dos seus pontos mais fortes. De outra parte, a insistência, até militante no caso de alguns autores, por uma abordagem eminentemente internalista só é compreensível quando se tem em conta o cenário político contemporâneo. Sem dúvida, todos os observadores 
interessados desejariam que Frelimo e Renamo se transformassem finalmente em partidos políticos "normais" na democracia representativa em que Moçambique deveria ter-se tornado depois de depostas as armas - sendo para isso imprescindível negar ao antigo partido-Estado sua recorrente pretensão de representar todo o povo, tanto quanto reconhecer na antiga guerrilha a expressão de demandas legítimas de parte da população moçambicana. Entretanto, fazer disto um cavalo de batalha no âmbito dos estudos sobre a guerra seria uma posição intelectual ingênua, e, como bem demonstra o último capítulo da obra, bastante limitadora. Especificamente com respeito à articulação entre fatores internos e externos, o livro termina não oferecendo uma "nova perspectiva", e sim a reedição pouco convincente de um debate em grande medida já esgotado. $\mathrm{Na}$ mesma linha, a defesa do termo "guerra civil" para indicar a familiaridade entre os inimigos, que seriam cidadãos de um mesmo país e não estrangeiros, resulta verdadeira apenas num sentido formal, já que a guerra se desenvolveu precisamente no contexto de legitimidades contestadas - do projeto nacionalista oficial da Frelimo, tanto quanto da alternativa representada pela Renamo. Em outras palavras, a comunidade política, ou uma determinada versão dela, era precisamente o que se estava lutando para impor à população do antigo território colonial. Derluguian lembra que, em muitas experiências históricas, as guerras fazem o Estado. Dolorosa como soe tal proposição, é possível que a guerra que assolou Moçambique durante tantos anos tenha sido a parteira da comunidade política.

Outra preocupação que emerge da leitura deste livro é a necessidade de colocar em questão o nosso entendimento do que seja a "população camponesa" de Moçambique e a condição de "base social" que esta população teria representado para um dos dois lados em disputa durante os anos da guerra. Colocar em relevo as estratégias de todos aqueles que tinham interesses investidos na "chefia tradicional" que supostamente já não existia, as relações dessas estruturas fantasmas com o Estado e seu significado prático para a organização da vida e da produção no interior de Moçambique nos permitiria superar a velha e enganosa dicotomia "tradição-modernidade" - que os autores não reclamam, mas em torno da qual alguns permanecem orbitando. Afinal, como se pode ler de passagem aqui e ali, nem todos os chefes tradicionais aderiram à Renamo, e sucessões ao cargo (inexistente) de régulo podiam descambar em confrontações físicas entre diferentes células da própria Frelimo. O caso dos naparamas é também ilustrativo, na medida que o rótulo "neotradicional" apenas ilude nosso desconcerto de não saber por que, afinal, eles tenderam para um dos lados do conflito, precisamente aquele que prometia extirpar da vida 
moçambicana o "obscurantismo" e a "superstição".

As sociedades camponesas moçambicanas estavam longe de ser monolíticas, mas continuamos reduzindo suas opções políticas a um movimento em bloco. Seria preciso, ainda, questionar as condições e limites em que um determinado indivíduo ou grupo pode "apoiar" organizações cujos representantes lhe chegam à porta com fuzis, fome, medo e muitas exigências. $\mathrm{O}$ paradigma subjacente de uma escotha racional não parece estar sendo seriamente problematizado, quando o contexto de zona de guerra prolongada cria dinâmicas liminares que colocam em suspenso pressupostos muito mais básicos que a preferência política, como o próprio valor da vida humana.

A guerra em Moçambique foi um dos muitos acontecimentos trágicos da história mundial recente, e nessa capacidade demanda, ainda, um esforço de explicação. O mérito deste livro, e seus organizadores o sabem, não é tanto o de propor novas e mais abrangentes interpretações conforme uma agenda de pesquisa bem estruturada, mas o de dar um renovado passo no sentido da ampliação do debate. Como tal, ele tem muito a contribuir para todos os interessados no estado da arte dos estudos sobre a África da segunda metade do século XX, e é de leitura obrigatória para aqueles que se debruçam a sério sobre a história moçambicana contemporânea.

Fábio Baqueiro Figueiredo Universidade da Integração Internacional da Lusofonia Afro-Brasileira - UNILAB fabiobaq@unilab.edu.br 